\title{
Araliasaponin II isolated from leaves of Acanthopanax henryi (Oliv.) Harms inhibits inflammation by modulating the expression of inflammatory markers in murine macrophages
}

\author{
YUN-SOO SEO ${ }^{1 *}$, SEOK-JEON LEE ${ }^{2 *}$, ZHI LI ${ }^{3}$, OK-HWA KANG ${ }^{1}$, RYONG KONG $^{1}$, SANG-A KIM ${ }^{1}$, \\ TIAN ZHOU ${ }^{1}$, YUNG-SUN SONG ${ }^{2}$, XIANGQIAN LIU ${ }^{3}$ and DONG-YEUL KWON ${ }^{1}$ \\ ${ }^{1}$ Department of Oriental Pharmacy, College of Pharmacy, Wonkwang Oriental Medicines Research Institute, \\ Wonkwang University; ${ }^{2}$ Professional Graduate School of Oriental Medicine, Department of Third Medicine, \\ Wonkwang University, Iksan, Jeollabuk 570749, Republic of Korea; ${ }^{3}$ School of Pharmacy, \\ Hunan University of Chinese Medicine, Changsha, Hunan 410208, P.R. China
}

Received May 16, 2016; Accepted March 7, 2017

DOI: $10.3892 / \mathrm{mmr} .2017 .6656$

\begin{abstract}
Araliasaponin II (AS II) is a bioactive compound isolated from Acanthopanax henryi (Oliv.) Harms, a plant widely used in traditional oriental medicine. The present study investigated the anti-inflammatory effects of AS II using murine macrophages. The effects of AS II on inflammatory mediator and cytokine production in lipopolysaccharide (LPS)-stimulated RAW 264.7 cells was evaluated. Nitric oxide (NO) and cytokine production were determined using the Griess reagent and an ELISA kit. The expression levels of cytokines, inducible NO synthase (iNOS) and cyclooxygenase-2 (COX-2) mRNA were examined by reverse transcription-quantitative polymerase chain reaction. The expression levels of iNOS, COX-2 and toll-like receptor (TLR)-4 protein were examined by western blotting. Translocation of nuclear factor- $\mathrm{\kappa B}(\mathrm{NF}-\mathrm{\kappa B})$ and TLR-4 expression were visualized by immunofluorescence staining. AS II markedly inhibited the production of $\mathrm{NO}$ and prostaglandin $\mathrm{E}_{2}$, and reduced iNOS and COX-2 expression at the transcriptional and translational levels. AS II downregulated the expression of interleukin- 6 and tumor necrosis factor- $\alpha$ at the protein and mRNA levels. Furthermore, pre-treatment with
\end{abstract}

Correspondence to: Professor Dong-Yeul Kwon, Department of Oriental Pharmacy, College of Pharmacy, Wonkwang Oriental Medicines Research Institute, Wonkwang University, 460 Iksandae-ro, Iksan, Jeollabuk 570749, Republic of Korea

E-mail: sssimi@wku.ac.kr

Professor Xiangqian Liu, School of Pharmacy, Hunan University of Chinese Medicine, 300 Xueshi Road, Changsha, Hunan 410208, P.R. China

E-mail: 1xq0001cn@163.com

*Contributed equally

Key words: araliasaponin II, anti-inflammatory, Toll-like receptor 4, nuclear factor- $\kappa \mathrm{B}$
AS II significantly suppressed the TLR-4-NF- $\mathrm{B}$ signaling pathway; this effect may be cause by AS II competing with LPS for binding to TLR-4 and subsequently inhibiting translocation of the NF- $\mathrm{kB} / \mathrm{p} 65$ protein to the nucleus. The results suggested that the anti-inflammatory properties of AS II may result from inhibiting pro-inflammatory mediators by suppressing the initiation of the inflammatory response and inhibiting TLR-4-NF- $\mathrm{kB}$ signaling pathways.

\section{Introduction}

Inflammation is a pathological response to protect against tissue injury following microbial invasion and is a key factor in various chronic and metabolic diseases $(1,2)$. Inflammation is a complex process that is regulated by an array of inflammatory factors released by activated immune cells (3). Activation of macrophages, which are key immune cells, by inflammatory stimuli is an important part of initiating defensive reactions. Activated macrophages release inflammatory mediators, including nitric oxide $(\mathrm{NO})$, prostaglandin $\mathrm{E}_{2}\left(\mathrm{PGE}_{2}\right)$ and pro-inflammatory cytokines that enhance defense capacity and induce a cascade of immune processes, including the activation of nitric oxide synthases (NOSs) and cyclooxygenase-2 (COX-2), which are main targets of anti-inflammatory agents $(4,5)$.

Nuclear factor- $\kappa \mathrm{B}(\mathrm{NF}-\kappa \mathrm{B})$ is largely associated with anti-inflammatory mediators, including $\mathrm{NO}, \mathrm{PGE}_{2}$, interleukin (IL)-6 and tumor necrosis factor (TNF)- $\alpha(6,7)$. Activated NF- $\mathrm{kB}$ is translocated into immune cell nuclei and mediates the expression of various pro-inflammatory and immune-regulatory cytokines (8). Toll-like receptors (TLRs) are pathogen-recognition receptors present on cell membranes and are major components of the innate immune system. TLRs are major initiators of the immune responses against various pathogens. In particular, TLR-4 is associated with lipopolysaccharide (LPS) at the beginning of the inflammatory response that occurs in various chronic diseases and complications, including aging, diabetes and cancer (9). Studies have demonstrated a close interaction between inflammatory factors in 
inflammation pathways and the oxidative stress that underlies chronic diseases $(10,11)$. Therefore, functional treatments should be developed to treat the underlying causes of clinical diseases.

Acanthopanax henryi (Oliv.) Harms is used in northeast Asian countries as a traditional therapeutic agent for the treatment of rheumatism, inflammation, sinew, bone pains, lameness and liver disease (12). A study (13) has suggested that the Acanthopanax leaves possess potential antioxidant activities and another (14) that Acanthopanax root bark extracts exhibit anti-inflammatory activities. Acanthopanax henryi (Oliv.) contains various bioactive compounds; however, few studies have been conducted on them. Therefore, the present study focused on araliasaponin II (AS II), one of the bioactive compounds from the leaves of Acanthopanax henryi, as a potential therapeutic agent for inflammation. As part of our continuing screening program to evaluate the anti-inflammatory potential of natural compounds, the anti-inflammatory effects of AS II were investigated and the potential mechanisms involved in its action on the LPS-stimulated immune response in murine macrophages was established.

\section{Materials and methods}

Plant collection. The leaves of Acanthopanax henryi (Oliv.) Harms were collected in October 2012 in Xinhua (Hunan, China), 230 km west from Hunan (latitude N 27 56' 16', longitude $\left.\mathrm{E} 111^{\circ} 21^{\prime} 22^{\prime}\right)$. The plant is not endangered or protected, and its identify was confirmed by Professor Liu Xiang-Qian (Hunan Key Laboratory of Traditional Chinese Medicine Modernization, Hunan University of Chinese Medicine, Changsha, China) and a voucher specimen (no. 20121125) was deposited within the School of Pharmacy, Hunan University of Chinese Medicine. No specific permission was required for collecting the plant.

Extraction and isolation. The dried leaves of Acanthopanax henryi (Oliv.) Harms (10 kg) were cut into small pieces and extracted three times with methanol ( $3 \times 1001)$ by soaking at room temperature, and then concentrated to give a dark-green residue $(0.8 \mathrm{~kg})$, which was suspended in $\mathrm{H}_{2} \mathrm{O}$ and separated with petroleum ether. The water fraction was fractionated by column chromatography (CC) on macroporous resin eluted with a gradient ethanol/ $\mathrm{H}_{2} \mathrm{O}(0,30,50,75$ and $95 \%)$ into five fractions, 1-5. Fraction 3 (75\% ethanol, $14.0 \mathrm{~g}$ ) was subjected to silica gel $\mathrm{CC}$ eluted with $\mathrm{CHCl}_{3} /$ methanol/ $\mathrm{H}_{2} \mathrm{O}(25: 1: 0 / 1: 1: 0.2)$ to give 15 fractions, A-O.

Fraction M (75 mg) was subjected to silica gel CC eluted with $\mathrm{CHCl}_{3} /$ methanol/ $\mathrm{H}_{2} \mathrm{O}(4: 1: 0.1 / 1: 1: 0.2)$ to give four sub-fractions, M1-M4 and M2-M4 were further separated using Sephadex LH-20 (methanol) to produce AS II (51 mg) (15).

The structures of the compounds were identified by mass spectrometry (MS), one-dimensional (1D)-nuclear magnetic resonance spectroscopy (NMR) and 2D-NMR, with a comparison of the spectral data with those reported previously in the literature (16).

High performance liquid chromatography (HPLC). The purity and content of AS II in the dried leaves of Acanthopanax henryi (Oliv.) Harms were determined by HPLC as previously described (17). Briefly, $4.88 \mathrm{mg}$ AS II was dissolved in $50 \mathrm{ml}$ $100 \%$ methanol to a final concentration of $0.0976 \mathrm{mg} / \mathrm{ml}$ for HPLC analysis. The dried leaves of Acanthopanax henryi (Oliv.) Harms (100 g) were cut into small pieces and extraction was performed three times using methanol ( $3 X{ }_{1} 1$ l) and reflux extraction at $65^{\circ} \mathrm{C}$ for $2 \mathrm{~h}$ each time. The extract was then concentrated to generate a dark-green residue, which was suspended in $100 \mathrm{ml} \mathrm{H}_{2} \mathrm{O}$ and separated with petroleum ether. The water fraction was fractionated by column chromatography $(80 \times 100 \mathrm{~mm})$ on D101 macroporous resin $(600 \mathrm{~g}$; Tianjin Guangfu Fine Chemical Research Institute, Tianjin, China) and eluted with a gradient of ethanol $/ \mathrm{H}_{2} \mathrm{O}(0,30$ and $75 \%$ ) into three fractions: Fractions 1 to 3 . Fraction 3 was concentrated, transferred into volumetric flasks and diluted with $100 \%$ menthol to $50 \mathrm{ml}$ to produce the sample for HPLC content analysis with a Kinetex XB-C18 analytical column (100x4.6x2.6-mm; Phenomenex, Inc., Torrance, CA, USA) at $30^{\circ} \mathrm{C}$. Elution was conducted using mobile phase A (water) and mobile phase $\mathrm{B}$ (acetonitrile) with a gradient as follows: 0-2 $\min , 29-31 \%$ B; 2-13 min, 31-35\% B; 13-15 min, 35-40\% B; $15-23 \mathrm{~min}, 40-44 \%$ B; 23-25 min, 44-46\% B; 25-31 min, 46-49\% B; 31-38 $\min , 49-55 \%$ B. The flow rate was kept constantly at $1.0 \mathrm{ml} / \mathrm{min}$, and the effluents were monitored at $210 \mathrm{~nm}$ using an Agilent 1200 HPLC system with a variable wavelength detector (Agilent Technologies, Inc., Santa Clara, CA, USA). The purity value of AS II, as evaluated by HPLC, was observed to be $>98 \%$ by the peak area normalization method. The value of purity was obtained by calculating the percentage of its peak area to that of the total peaks in the HPLC chromatogram. The content of AS II in the leaves of Acanthopanax henryi (Oliv.) Harms was $3.28 \mathrm{mg} / 100 \mathrm{~g}$, which was determined using the external standard method with the isolated AS II as standard.

General experimental procedures. Melting points (uncorrected) were measured using a Boetius micromelting point apparatus. Hydrogen-1-NMR (600 MHz), Carbon-13-NMR $(150 \mathrm{MHz})$ and 2D-NMR were recorded at room temperature in methanol or pyridine-d5 using a Bruker ACF-500 NMR spectrometer (Bruker Corporation, Billerica, MA, USA) and chemical shifts were presented in $\delta(\mathrm{ppm})$ values relative to tetramethylsilane as an internal standard. Mass spectra were obtained on an MS Agilent 1200 Series LC/MSD Trap Mass spectrometer (ESI-MS; Agilent Technologies, Inc.). Column chromatography was carried out on silica gel (200-300 mesh and 100-200 mesh; Qingdao Marine Chemical Inc., Qingdao, China), Sephadex LH-20 (Merck KGaA, Darmstadt, Germany) and D101 macroporous resin (Tianjin Guangfu Chemical Co., Ltd., Tianjin, China). Reversed-phase thin-layer chromatography was performed on a precoated RP-18F254s plates (Merck KGaA). Thin-layer chromatography was conducted on self-made silica gel G (Qingdao Marine Chemical, Inc.) plates and spots were visualized by spraying with $10 \% \mathrm{H}_{2} \mathrm{SO}_{4}$ in ethanol (v/v) followed by heating at $105^{\circ} \mathrm{C}$.

Reagents.RPMI-1640,penicillinandstreptomycinwereobtained from Hyclone (GE Healthcare Life Sciences, Logan, UT, USA). Bovine serum albumin, LPS, 3-(4,5-dimethylthiazol-2-yl)-5(3-carboxymethoxyphenyl)-2-(4-sulfophenyl)-2H-tetrazolium (MTS) and 4',6-diamidino-2-phenylindole (DAPI) were 
purchased from Sigma-Aldrich (Merck KGaA). Inducible NOS (iNOS; cat. no. sc-651), COX-2 (cat. no. sc-1745), TLR-4 (cat. no. sc-16240), NF-кB (cat. no. sc-8008), $\beta$-actin (cat. no. sc-47778) and peroxidase-conjugated secondary antibodies (anti-mouse, cat. no. sc-2005; anti-rabbit, cat. no. sc-2004; anti-goat, cat. no. sc-2020) were purchased from Santa Cruz Biotechnology, Inc. (Santa Cruz, CA, USA). Mouse IL-6 ELISA kit (cat. no. 555240) and mouse TNF- $\alpha$ (mono/mono) ELISA kit (cat. no. 555268) were purchased from BD Biosciences (San Jose, CA, USA). PRO-PREP ${ }^{\text {Tм }}$ Protein Extraction Solution was purchased from Intron Biotechnology, Inc. (Seongnam, Korea). An RNeasy Mini kit and a QuantiTect Reverse Transcription kit were purchased from Qiagen $\mathrm{GmbH}$ (Hilden, Germany). Finally, fluorochrome-conjugated secondary antibodies (anti-mouse, cat. no. A-11029 and anti-goat, cat. no. A-21432) and fluorochrome-conjugated LPS (cat. no. L-23351) were purchased from Thermo Fisher Scientific, Inc. (Waltham, MA, USA).

Cell culture. The RAW 264.7 cells were obtained from the Korea Research Institute of Bioscience and Biotechnology (Seoul, Korea) and cultured in RPMI 1640 medium supplemented with $10 \%$ fetal bovine serum and $100 \mathrm{U} / \mathrm{ml}$ of penicillin/streptomycin sulfate. The cells were cultured in a humidified incubator with $5 \% \mathrm{CO}_{2}$ atmosphere at $37^{\circ} \mathrm{C}$. To stimulate the cells, the medium was replaced with fresh RPMI 1640 medium followed by addition of LPS in the presence or absence of AS II for the indicated periods.

MTS assay. An MTS assay was used to determine the viability of RAW 264.7 cells. Cells $\left(5 \times 10^{4}\right.$ cells per well) were plated in 96-well plates (SPL Life Sciences, Pocheon, Korea). Cells were treated without or with AS II (10,20 and $40 \mu \mathrm{M})$ and the plates were incubated for $24 \mathrm{~h}$ at $37^{\circ} \mathrm{C}$ followed by a further $2 \mathrm{~h}$ with MTS solution ( $5 \mathrm{mg} / \mathrm{ml})$. Optical density was measured at $490 \mathrm{~nm}$. Cell viability was calculated using the formula (mean absorbance value of treated cells/mean absorbance value of untreated cells)x 100 .

Nitrite production. The cells were seeded at $5 \times 10^{4}$ per well in 96-well culture plates. The RAW 264.7 cells were stimulated with LPS (200 ng/ml) without or with AS II (10, 20 and $40 \mu \mathrm{M})$ for $24 \mathrm{~h}$. Nitrite in the cultured RAW 264.7 cell supernatant was determined using Griess reagent (1\% sulfanilamide, $0.1 \%$ naphthylethylenediamine dihydrochloride and $2.5 \%$ phosphoric acid). An equal volume of Griess reagent was mixed with the supernatant and incubated at room temperature for $5 \mathrm{~min}$. Nitrite concentrations were measured at $570 \mathrm{~nm}$ using an Epoch microplate spectrophotometer (Biotek Instruments, Inc., Winooski, VT, USA). A sodium nitrite $\left(\mathrm{NaNO}_{2}\right)$ standard curve was used to calculate nitrite concentration.

Prostaglandin $E_{2}$ production. The amount of $\mathrm{PGE}_{2}$ was determined using a $\mathrm{PGE}_{2}$ Enzyme Immuno-Assay kit (GE Healthcare Life Sciences, Chalfont, UK) according to the manufacturer's protocols. Briefly, $2.5 \times 10^{5}$ RAW 264.7 cells per well were cultured in 24-well culture plates. AS II (10, 20 and $40 \mu \mathrm{M})$ and LPS (200 $\mathrm{ng} / \mathrm{ml})$ was added to each well and incubated at $37^{\circ} \mathrm{C}$ for $24 \mathrm{~h}$. The supernatant was collected and used to measure $\mathrm{PGE}_{2}$ production.
Enzyme-linked immunosorbent assay (ELISA). RAW 264.7 macrophages $\left(2.5 \times 10^{5}\right.$ per well) were cultured in 24 -well plates and treated with LPS $(200 \mathrm{ng} / \mathrm{ml})$ in the presence or absence of AS II (10, 20 and $40 \mu \mathrm{M})$ for $24 \mathrm{~h}$. Levels of TNF- $\alpha$ and IL-6 in the culture media were quantified using ELISA kits, according to the manufacturer's protocols (BD Biosciences). Briefly, ELISA plates (Nalge Nunc International; Thermo Fisher Scientific, Inc.) were coated overnight with coating buffer including anti-mouse IL-6 and TNF- $\alpha$ antibodies. The wells were washed and the samples and standards added. Following a $2 \mathrm{~h}$ incubation, biotinylated anti-mouse IL-6 monoclonal antibody and biotinylated anti-mouse TNF- $\alpha$ with streptavidin-horseradish peroxidase reagent were added each well and incubated for $1 \mathrm{~h}$. The wells were washed and the tetramethylbenzidine substrate solution added to the wells and incubated for $30 \mathrm{~min}$ in the dark. A stop solution $\left(2 \mathrm{~N} \mathrm{H}_{3} \mathrm{PO}_{4}\right)$ was added and absorbance was read at $450 \mathrm{~nm}$.

Western blot analysis. RAW 264.7 cells were plated at $6 \times 10^{6}$ cells per well in 6 -well culture plates and treated with LPS $(200 \mathrm{ng} / \mathrm{ml})$ in the presence or absence of AS II (10, 20 and $40 \mu \mathrm{M}$ ) for $24 \mathrm{~h}$ at $37^{\circ} \mathrm{C}$. Following incubation, the cell pellets were lysed in PRO-PREP ${ }^{\mathrm{TM}}$ Protein Extraction Solution on ice for $20 \mathrm{~min}$. Protein levels in collected supernatants were determined using the Bio-Rad protein assay reagent (Bio-Rad Laboratories, Inc., Hercules, CA, USA) according to the manufacturer's protocols. Sodium dodecyl sulfate-polyacrylamide gel (10\% for iNOS and COX-2; $12 \%$ for TLR-4) electrophoresis were performed with equal amounts of protein (240 ng/lane) and transferred onto polyvinylidene membranes (EMD Millipore, Billerica, MA, USA). Following blocking with TBS-T [20 mM/l Tris- $\mathrm{HCl}(\mathrm{pH} 7.6)$, $137 \mathrm{mM} / 1 \mathrm{NaCl}, 0.05 \%$ Tween 20] containing 5\% skimmed milk, the membranes were incubated overnight at $4^{\circ} \mathrm{C}$ with primary antibodies $(1: 1,000)$. The membranes were washed with TBS-T and incubated for $1 \mathrm{~h}$ at room temperature with anti-mouse, anti-goat or anti-rabbit immunoglobulin $\mathrm{G}$ horseradish peroxidase-conjugated secondary antibodies $(1: 2,000)$. The bands were evaluated by using ECL Prime Western Blotting Detection Reagent and an ImageQuant LAS 4000 Mini BioMolecular Imager (GE Healthcare).

RNA extraction and reverse transcription-quantitative polymerase chain reaction (RT-qPCR). RAW 264.7 cells were plated at $6 \times 10^{6}$ cells per well in 6 -well culture plates and treated with LPS $(200 \mathrm{ng} / \mathrm{ml})$ in the presence or absence of $\operatorname{AS}$ II $(10,20$ and $40 \mu \mathrm{M})$ for $24 \mathrm{~h}$ at $37^{\circ} \mathrm{C}$. Following incubation, an RNeasy Mini kit was used to isolate total cell RNA. Then, $1 \mu \mathrm{g}$ total RNA was reverse-transcribed into cDNA using the QuantiTect Reverse Transcription kit (Qiagen $\mathrm{GmbH}$ ) according to the manufacturer's protocols. RT-qPCR was performed using power SYBR ${ }^{\circledR}$ Green PCR master mix according to the manufacturer's protocols. PCR thermocycling conditions were as follows: Holding stage, 1 cycle of $95^{\circ} \mathrm{C}$ for $10 \mathrm{~min} ; 40$ cycles of $95^{\circ} \mathrm{C}$ for $15 \mathrm{sec}$ and $60^{\circ} \mathrm{C}$ for $1 \mathrm{~min} ; 1$ cycle of $95^{\circ} \mathrm{C}$ for $15 \mathrm{sec}, 60^{\circ} \mathrm{C}$ for $1 \mathrm{~min}$ and $95^{\circ} \mathrm{C}$ for $\left.15 \mathrm{sec}\right)$. The PCR products were measured with a StepOnePlus Real-Time RT-PCR System. Relative gene expression was calculated based on the $2^{-\Delta \Delta \mathrm{Cq}}$ method (18) using StepOne software version 2.3 (Applied Biosystems, 
Table I. Sequences of primers used for reverse transcription-quantitative polymerase chain reaction.

\begin{tabular}{lll}
\hline Gene & \multicolumn{1}{c}{ Forward (5'-3') } & \multicolumn{1}{c}{ Reverse (5'-3') } \\
\hline iNOS & GCAGAGATTGGAGGCCTTGTG & GGGTTGTTGCTGAACTTCCAGTC \\
COX-2 & GCCAGGCTGAACTTCGAAACA & CAGATGACCTAGTAACGGACT \\
IL-6 & TCTATACCACTTCACAAGTCGGA & GAATTGCCATTGCACAACTCTT \\
TNF- $\alpha$ & ATGAGCACTGAAAGCATGATC- & CATCCGTAAAGACCTCTATGCCAAC \\
$\beta$-actin & CATCCGTAAAGACCTCTATGCCAAC & ATGGAGCCACCGATCCACA
\end{tabular}

iNOS, inducible nitric oxide synthase; COX-2, cyclooxygenase-2; IL-6, interleukin-6; TNF- $\alpha$, tumor necrosis factor- $\alpha$.
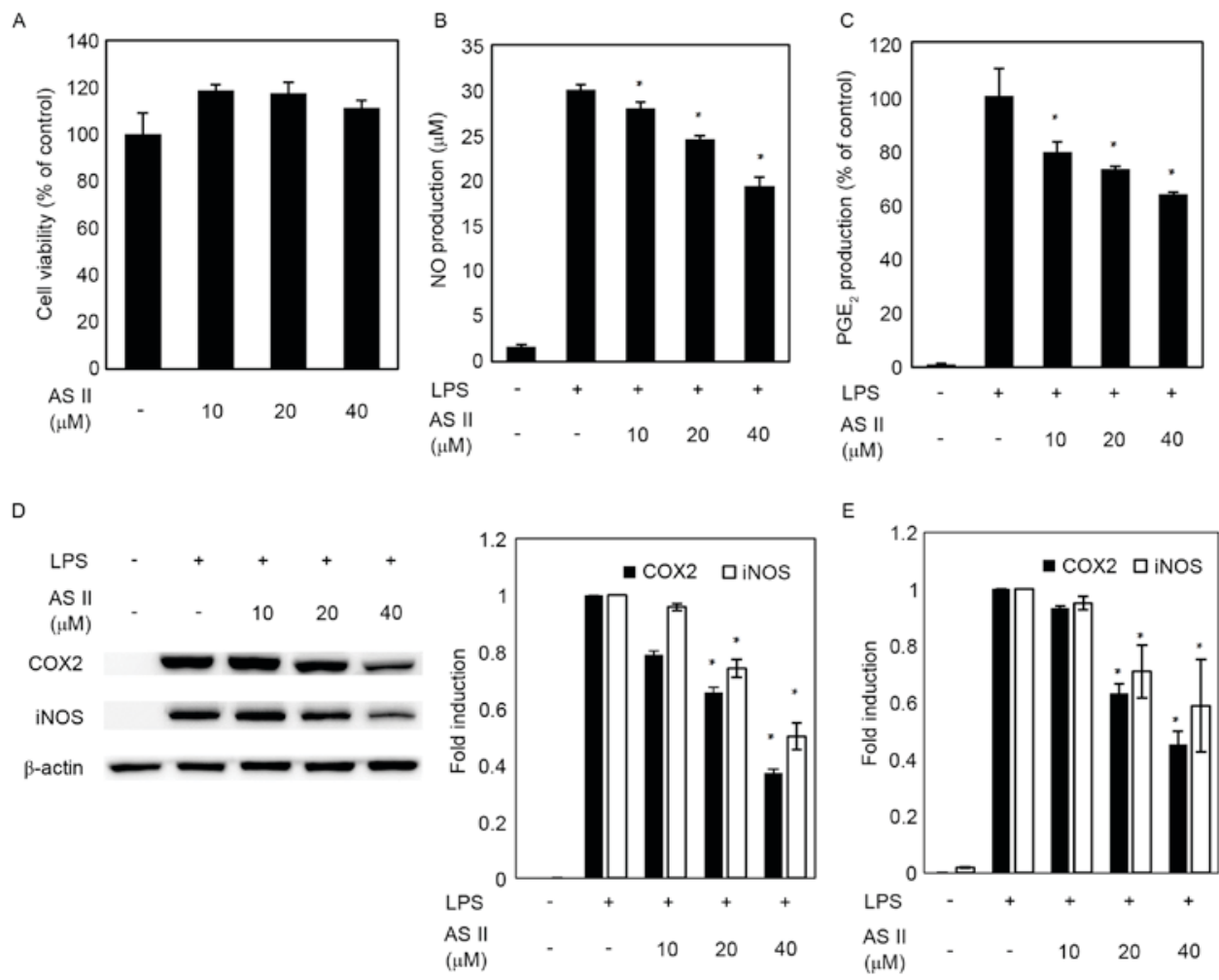

Figure 1. Effect of AS II on cell viability and inflammatory mediators, NO, $\mathrm{PGE}_{2}, \mathrm{COX} 2$ and iNOS in RAW 264.7 cells. (A) Cell viability was evaluated

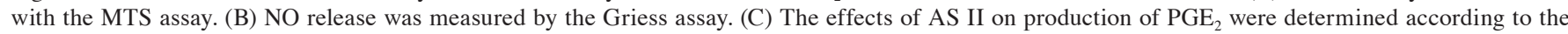
manufacturer's protocol. (D) Cells used in the western blot analysis and (E) reverse transcription-quantitative polymerase chain reaction were pretreated with AS II for $30 \mathrm{~min}$ and then incubated with LPS $(200 \mathrm{ng} / \mathrm{ml})$ for $24 \mathrm{~h}$. Representative western blotting of at least three separate experiments are demonstrated. ${ }^{*} \mathrm{P}<0.05$ vs. LPS-treated group. Significant differences between the treated groups were determined using analysis of variance followed by Scheffe's test for multiple comparisons. Values are means \pm standard deviations of duplicate determinations from three separate experiments. AS II, araliasaponin II; NO, nitric oxide; $\mathrm{PGE}_{2}$, prostaglandin $\mathrm{E}_{2}$; iNOS, inducible nitric oxide synthase; COX-2, cyclooxygenase-2; LPS, lipopolysaccharide.

Foster City, CA, USA). $\beta$-actin mRNA expression was used as an endogenous control. Primer sets for RT-qPCR are presented in Table I.

Immunofluorescence staining. RAW 264.7 cells were cultured in chambered cover glasses (Nalge Nunc International; Thermo Fisher Scientific, Inc.) for $24 \mathrm{~h}$ and stimulated with LPS in the presence or absence of AS II. The cells were fixed in $4 \%$ formaldehyde in PBS for $15 \mathrm{~min}$ at room temperature and permeabilized with $100 \%$ methanol for $10 \mathrm{~min}$ at $-20^{\circ} \mathrm{C}$. Specimens were blocked with blocking buffer (PBS with 5\% serum and $0.3 \%$ Triton $\mathrm{X}-100)$ for $1 \mathrm{~h}$ and incubated overnight with polyclonal antibodies $(1: 200)$ at $4^{\circ} \mathrm{C}$. Fluorochrome-conjugated secondary antibodies (1:500) were applied for $1 \mathrm{~h}$ at room temperature in the dark. Following washing with PBS, the nuclei were counterstained with DAPI and fluorescence was visualized using a fluorescence microscope (Ziess AG, Oberkochen, Germany). AlexaFluor 488-conjugated LPS was used to evaluate the effects of AS II on LPS and TLR-4 binding.

Statistical analyses. The statistical analysis was performed using one-way analysis of variance followed by Scheffe's test for multiple comparisons. Data are presented as mean \pm standard deviation $(n=5)$. All calculations were performed using SPSS statistics version 22 software (IBM SPSS, Armonk, NY, USA). $\mathrm{P}<0.05$ was considered to indicate a statistically significant difference. 

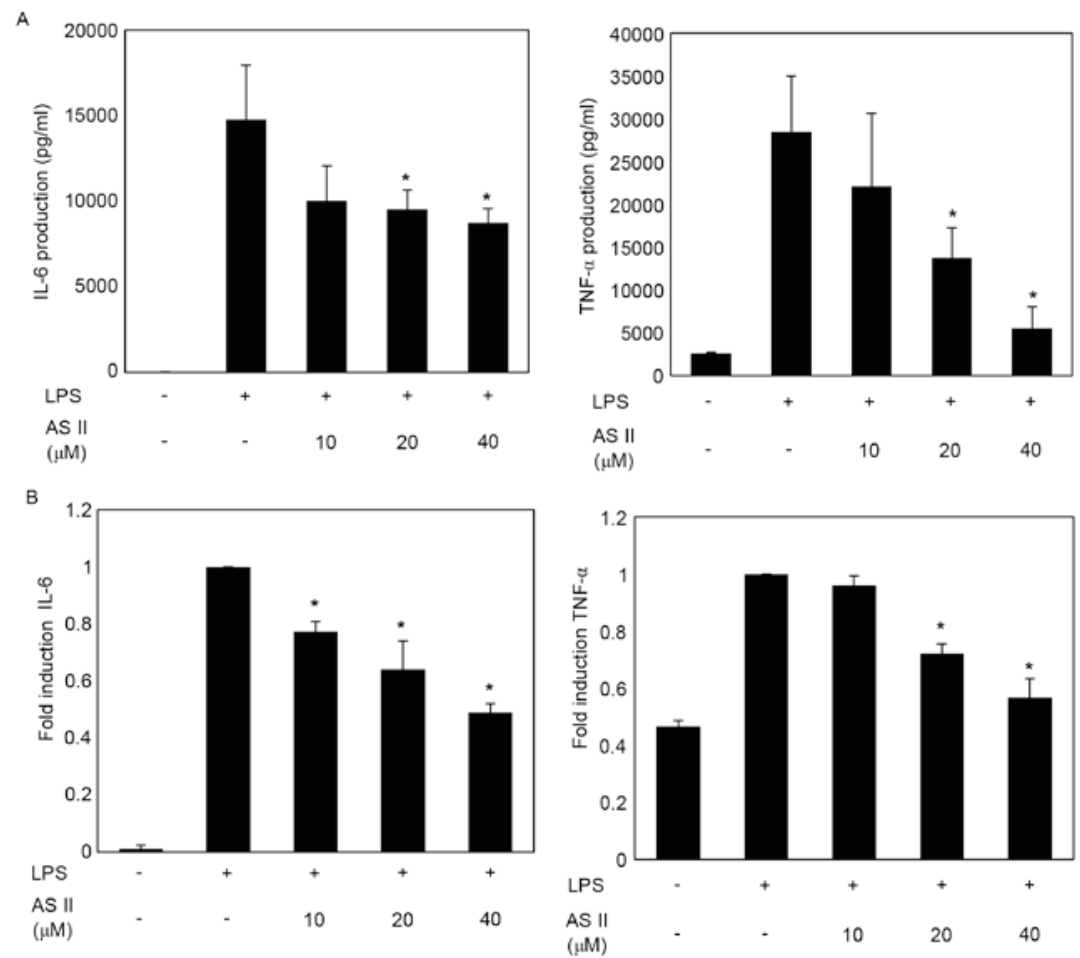

Figure 2. Effect of AS II on LPS-induced IL-6 and TNF- $\alpha$ production in RAW 264.7 cells. The culture supernatant was isolated and analyzed to measure (A) IL-6 and TNF- $\alpha$ production. (B) IL-6 and TNF- $\alpha$ expression levels in mRNA levels were evaluated by reverse transcription-quantitative polymerase chain reaction. ${ }^{*} \mathrm{P}<0.05$ vs. LPS-treated group. Significant differences between treated groups were determined using Student's t-test. Values are means \pm standard errors of duplicate determinations from three separate experiments. AS II, araliasaponin II; LPS, lipopolysaccharide; IL-6, interleukin-6; TNF- $\alpha$, tumor necrosis factor- $\alpha$.

\section{Results}

AS II inhibits LPS-induced $N O$ and $P G E_{2}$ production and downregulated $i N O S$ and COX-2 expression. MTS assays were performed to determine the effects of AS II on murine macrophage viability (Fig. 1A). The following experiments were accomplished using $40 \mu \mathrm{M}$ AS II to evaluate its anti-inflammatory effects. As demonstrated in Fig. 1B and C, LPS increased production of $\mathrm{NO}$ and $\mathrm{PGE}_{2}$ compared with the untreated group. However, groups pretreated with AS II had significantly decreased levels of $\mathrm{NO}$ and $\mathrm{PGE}_{2}$ production in LPS-stimulated RAW 264.7 cells in a dose-dependent manner up to $40 \mu \mathrm{M}$. The effects of AS II on iNOS and COX-2 protein and mRNA expression were examined. iNOS and COX-2 mRNA and protein expression levels were undetectable in the unstimulated group; however, iNOS and COX-2 expression increased significantly in response to LPS. AS II reduced COX-2 protein and mRNA expression by 37 and $45 \%$, respectively, at the highest concentration compared with LPS-treated cells. AS II $(40 \mu \mathrm{M})$ decreased iNOS protein and mRNA expression by 50 and $59 \%$, respectively, relative to the LPS=treated group (Fig. 1D and E).

AS II suppresses LPS-induced IL-6 and TNF- $\alpha$ production and $m R N A$ expression. The effects of AS II on synthesis of the pro-inflammatory cytokines IL- 6 and TNF- $\alpha$ in LPS-stimulated murine macrophages were investigated. Significantly increased levels of IL- 6 and TNF- $\alpha$ following treatment with LPS were reduced by pretreatment with AS II (Fig. 2A). The RT-qPCR data demonstrated that AS II reduced the mRNA of these cytokines. IL- 6 and TNF- $\alpha$ mRNA expression levels were decreased by up to 49 and $56.8 \%$ respectively, compared with the LPS only treated group (Fig. 2B).

AS II blocks $N F-\kappa B$ nuclear translocation in murine macrophages. Previous studies have demonstrated that $N F-\kappa B$ is a key transcriptional factor involved in regulating inflammatory mediators, including iNOS, COX-2 and cytokines. As demonstrated in Fig 3, NF- $\mathrm{B}$ nuclear translocation was increased in the LPS-stimulated group compared with the untreated group. $\mathrm{NF}-\kappa \mathrm{B}$ nuclear translocation decreased significantly when AS II was added with LPS (Fig. 3).

AS II decreases recognition of LPS and downregulates TLR-4. The LPS-activated TLR-4 signaling pathway was analyzed by western blot analysis and immunofluorescence staining. Receptor expression was studied $24 \mathrm{~h}$ following LPS treatment. TLR-4 expression in LPS-stimulated murine macrophages increased from undetectable levels compared with untreated macrophages. TLR-4 expression was decreased in the experimental groups treated with LPS and AS II. In addition, high fluorescence intensity was observed outside the cell membrane when cells were stimulated with fluorescent-dye conjugated LPS; however, fluorescence intensity weakened in the presence of AS II (Fig. 4).

\section{Discussion}

The present study examined the potential anti-inflammatory effects of AS II and investigated whether AS II regulates the 


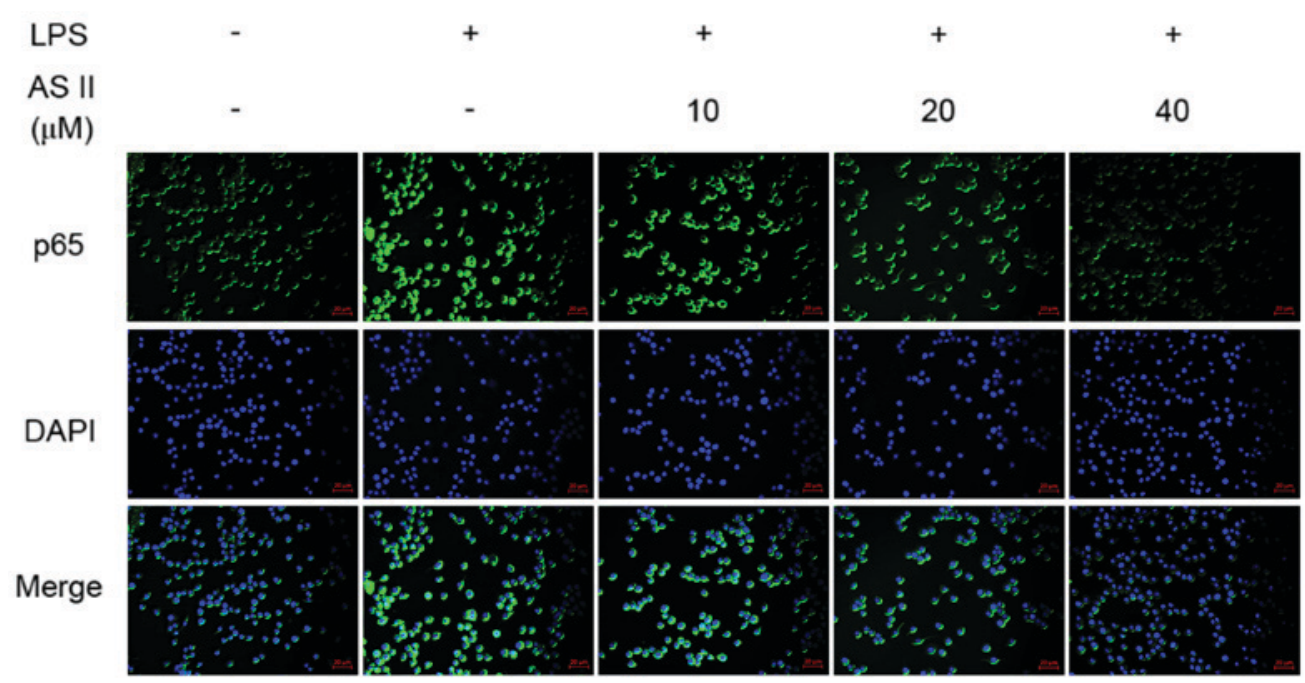

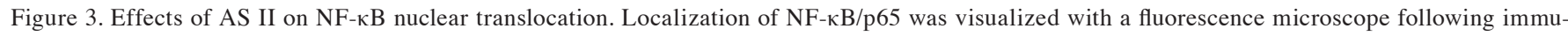
nofluorescence staining. Nuclei were counterstained with DAPI. Similar results were obtained in three independent experiments and results of one

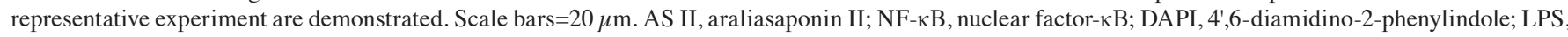
lipopolysaccharide.

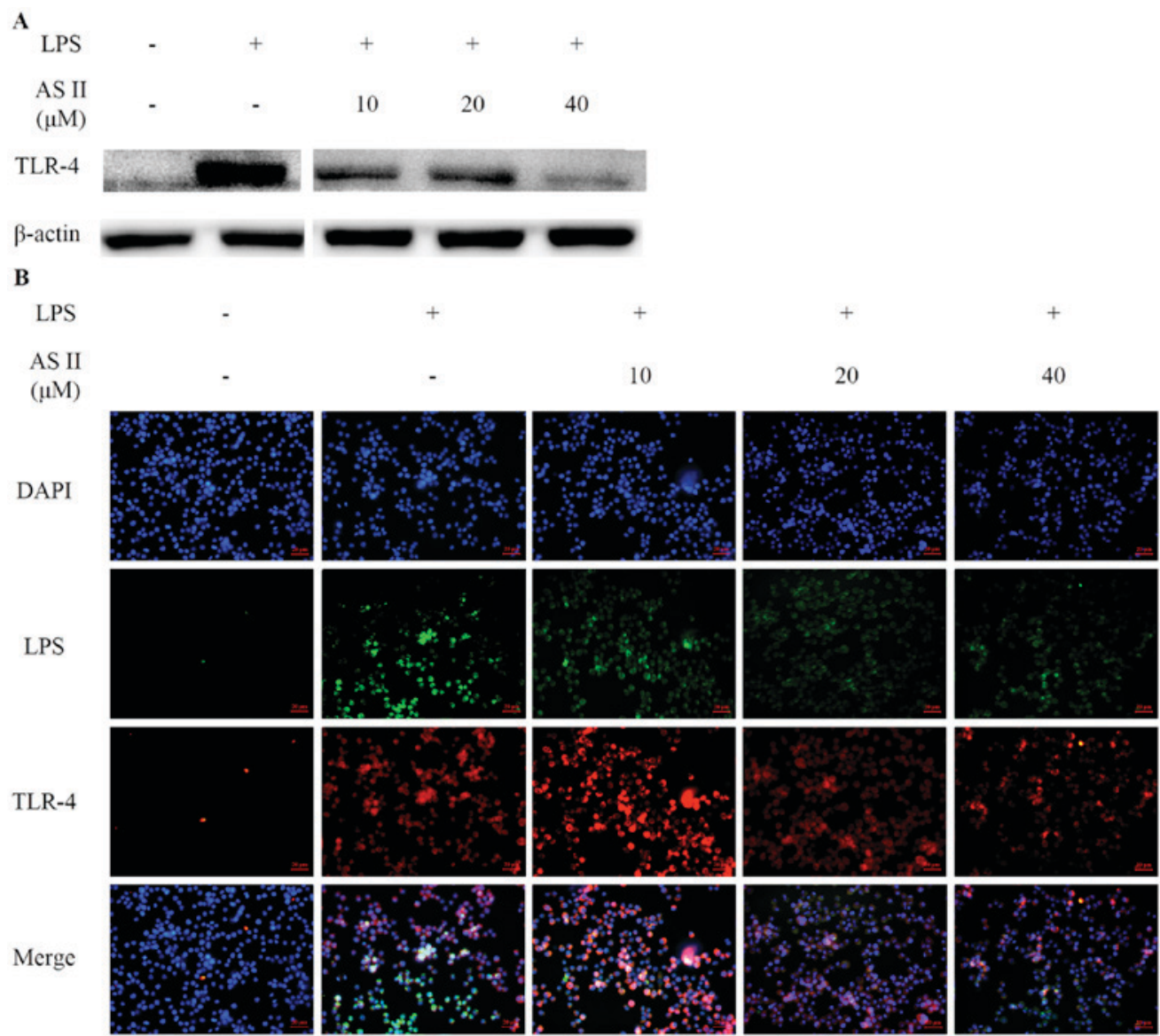

Figure 4. Effects of AS II on TLR-4 expression and the interaction between LPS and TLR-4. Cells used in (A) western blot analysis and (B) immunofluorescence staining were pretreated with AS II for $30 \mathrm{~min}$ and then incubated with LPS (200 ng/ml) for $24 \mathrm{~h}$. Representative western blots of at least three separate experiments are demonstrated. Interactions between LPS and TLR-4 were visualized with a fluorescence microscope following immunofluorescence staining. Nuclei were counterstained with DAPI. Similar results were obtained in three independent experiments and the results of one representative experiment are presented. AS II, araliasaponin II; LPS, lipopolysaccharide; TLR-4, Toll-like receptor 4; DAPI, 4',6-diamidino-2-phenylindole.

inflammatory response by suppressing signaling pathways in an LPS-stimulated inflammatory model. NO, which is a reactive oxygen species, is a frontline immune response effector molecule that attacks foreign agents but also has strong cytotoxic effects related with a number of inflammatory diseases (19). Thus, NO is considered an important 
inflammation parameter (20). Excess production of NO and $\mathrm{PGE}_{2}$ following an infection is caused by expression of iNOS, which is involved in the synthesis of NO and COX-2, which is the rate-limiting enzyme catalyzing conversion of arachidonic acid. Therefore, $\mathrm{NO}$ and $\mathrm{PGE}_{2}$ are key downstream effectors of iNOS and COX-2 during inflammation (21). The current study identified that AS II reduced LPS-induced NO production and $\mathrm{PGE}_{2}$ expression in murine macrophages. In addition, iNOS and COX-2 protein and mRNA overexpression decreased following pretreatment with AS II. These results indicated that the effects of $\mathrm{AS}$ II on $\mathrm{NO}$ and $\mathrm{PGE}_{2}$ production may be caused by suppression of iNOS and COX-2 expression.

IL- 6 and TNF- $\alpha$ are important inflammatory factors in immune responses, including fever and the acute phase response. Macrophages express the pro-inflammatory cytokines TNF- $\alpha$ and IL- 6 during inflammation, in addition to other inflammatory factors, including NO and PGs, that initiate the transfer of additional immune cells to the sites of infection or tissue injury (22). As demonstrated in the present study, LPS stimulation increased TNF- $\alpha$ and IL-6 expression in RAW 264.7 cells but AS II downregulated TNF- $\alpha$ and IL-6 protein and mRNA expression levels. These results suggest that AS II exhibits anti-inflammatory activity by inhibiting the expression of pro-inflammatory mediators.

One of the notable findings of the present study was the identification of the effect of AS II on the nuclear translocation of p65, a component of NF- $\kappa \mathrm{B}$ induced by LPS. It was demonstrated that AS II reduced nuclear translocation of NF- $\kappa$ B. A heterodimer of $\mathrm{p} 65$ and $\mathrm{p} 50$, another $\mathrm{NF}-\kappa \mathrm{B}$ component, binds to inhibitory $\kappa \mathrm{B}$, which is an inhibitor of $\mathrm{NF}-\kappa \mathrm{B}$. LPS-induced phosphorylation of inhibitory $\kappa \mathrm{B}$ releases $\mathrm{NF}-\kappa \mathrm{B}$ and allows $\mathrm{NF}-\kappa \mathrm{B}$ to translocate to the nucleus. Due to this p65 transactivation activity, a key process of $N F-\kappa B$ activation is nuclear translocation of p65 into the nucleus $(23) . N F-\kappa B$ is an important transcription factor that regulates immune and inflammatory signaling by promoting the transcription of pro-inflammatory mediators, including iNOS, COX-2 and cytokines, and translocation of $\mathrm{NF}-\kappa \mathrm{B}$ has been described as a rate-limiting step (24). Thus, the inhibitory effect of AS II on inflammatory mediators may be mediated by blocking the activation of $\mathrm{NF}-\kappa \mathrm{B}$.

TLRs are the first to recognize various microbial pathogens that invade the body, including LPS. TLRs initiate downstream pro-inflammatory activities leading to the innate immune response (25). The immune response triggered by interactions between pathogens and TLRs operate an acute and early release of inflammatory mediators. Among them, TLR-4 is the most important receptor that recognizes LPS. The TLR-4 signaling pathway is indispensable for LPS-stimulated NO production in inflammatory cells (26). LPS interacts with TLR-4 by binding to cell membranes, resulting in downstream inflammatory events, which may be responsible for inflammatory disorders (27). LPS-stimulated TLR-4 triggers enhanced NO, TNF- $\alpha$ and IL-6 expression through the TLR-4-NF- $\mathrm{B}$ signaling pathway, which mediates host damage (28). The effects of AS II on the interaction between LPS and TLR-4 in RAW 264.7 macrophage cells was investigated in the current study. The observations from the present study demonstrated that AS II pretreatment markedly attenuated LPS binding to TLR-4 on the cell surface, suggesting that AS II may interfere with TLR-4 clustering. In addition, pretreatment with AS II markedly inhibited LPS-induced TLR-4 expression in RAW 264.7 cells. These observations suggested that the subsequently suppressed activation of the $\mathrm{NF}-\kappa \mathrm{B}$ signaling pathway by AS II is induced by inhibiting initiation of the intracellular signaling cascade. Previous studies have indicated that certain anti-inflammatory agents compete with LPS for TLR-4 binding, resulting in the downregulation of downstream signaling pathways $(29,30)$. Therefore, the antagonistic function of AS II against TLR-4 may be responsible for the anti-inflammatory effects of AS II in LPS-stimulated RAW 264.7 macrophages.

Previous studies have reported that the TLR4-NFאB signaling pathway is the main mechanism for the inflammatory response following LPS stimulation $(31,32)$. The results of the present study demonstrated that AS II exerted anti-inflammatory actions that may be mediated by inhibition of LPS-TLR-4 binding in activated RAW 264.7 cells. Other experiments demonstrated that AS II inhibited NO production in murine macrophages and attenuated the LPS-induced inflammatory response by downregulating the $\mathrm{NF}-\kappa \mathrm{B}$ pathway. It is hypothesized that AS II inhibits downstream inflammatory mediators (iNOS and COX-2) and markers (NO, $\mathrm{PGE}_{2}$, IL-6 and TNF- $\alpha$ ) through this action. Therefore, the results of the present study indicated that AS II may be useful for the prevention of inflammatory diseases.

\section{Acknowledgements}

The present study was supported by Wonkwang University (Jeollabuk, Korea) in 2017.

\section{References}

1. Cho YC, Ju A, Kim BR and Cho S: Anti-inflammatory effects of Crataeva nurvala Buch. Ham. Are mediated via inactivation of ERK but not NF- $\kappa$ B. J Ethnopharmacol 162: 140-147, 2015.

2. Chawla A, Nguyen KD and Goh YP: Macrophage-mediated inflammation in metabolic disease. Nat Rev Immunol 11: 738-749, 2011.

3. Jang JC and Nair MG: Alternatively activated macrophages Revisited: New insights into the regulation of immunity, inflammation and metabolic function following parasite infection. Curr Immunol Rev 9: 147-156, 2013.

4. Sharma JN, Al-Omran A and Parvathy SS: Role of nitric oxide in inflammatory diseases. Inflammopharmacology 15: 252-259, 2007.

5. Zhou R, Shi X, Gao Y, Cai N, Jiang Zand Xu X: Anti-inflammatory activity of guluronate oligosaccharides obtained by oxidative degradation from alginate in lipopolysaccharide-activated murine macrophage RAW 264.7 cells. J Agric Food Chem 63: $160-168,2015$.

6. Ci X, Ren R, Xu K, Li H, Yu Q, Song Y, Wang D, Li R and Deng $X$ : Schisantherin A exhibits anti-inflammatory properties by down-regulating NF-kappaB and MAPK signaling pathways in lipopolysaccharide-treated RAW 264.7 cells. Inflammation 33: 126-136, 2010.

7. Mi Jeong Sung, Davaatseren M, Kim W, Sung Kwang Park, Kim SH, Haeng Jeon Hur, Myung Sunny Kim, Kim YS and Dae Young Kwon: Vitisin A suppresses LPS-induced NO production by inhibiting ERK, p38, and NF-kappaB activation in RAW 264.7 cells. Int Immunopharmacol 9: 319-323, 2009.

8. Sun SC, Chang JH and Jin J: Regulation of nuclear factor- $\kappa \mathrm{B}$ in autoimmunity. Trends Immunol 34: 282-289, 2013.

9. Mayne ST: Antioxidant nutrients and chronic disease: Use of biomarkers of exposure and oxidative stress status in epidemiologic research. J Nutr 133 (Suppl 3): 933S-940S 2003.

10. Gratas-Delamarche A, Derbré F, Vincent S and Cillard J: Physical inactivity, insulin resistance, and the oxidative-inflammatory loop. Free Radic Res 48: 93-108, 2014. 
11. Golbidi S, Badran M and Laher I: Antioxidant and anti-inflammatory effects of exercise in diabetic patients. Exp Diabetes Res 2012: 941868, 2012.

12. Kim JH, Liu XQ, Dai L, Yook CS and Lee KT: Cytotoxicity and anti-inflammatory effects of root bark extracts of Acanthopanax henryi. Chin J Nat Med 12: 121-125, 2014.

13. Zhang XD, Liu XQ, Kim YH and Whang WK: Chemical constituents and their acetyl cholinesterase inhibitory and antioxidant activities from leaves of Acanthopanax henryi: Potential complementary source against Alzheimer's disease. Arch Pharm Res 37: 606-616, 2014.

14. Kim JH, Liu XQ, Dai L, Yook CS and Lee KT: Cytotoxicity and anti-inflammatory effects of root bark extracts of Acanthopanax henryi. Chin J Nat Med 12: 121-125, 2014.

15. Miyase T, Shiokawa KI, Zhang DM and Ueno A: Araliasaponins I-XI, triterpene saponins from the roots of Aralia descaisneana. Phytochemistry 41: 1411-1418, 1996.

16. Shao CJ, Ryoji Kasai, Xu JD and Tanaka O: Saponins from leaves of Acanthopanax senticosus Harms., Ciwujia: Structures of Ciwujianosides B, C1, C2, C3, C4, D1, D2 and E. Chem Pharm Bull 36: 601-608, 1988.

17. Zhang XD, Li Z, Liu GZ, Wang X, Kwon OK, Lee HK, Whang WK and Liu X: Quantitative determination of 15 bioactive triterpenoid saponins in different parts of Acanthopanax henryi by HPLC with charged aerosol detection and confirmation by LC-ESI-TOF-MS. J Sep Sci 39: 2252-2262, 2016.

18. Livak KJ and Schmittgen TD: Analysis of relative gene expression data using real-time quantitative PCR and the 2(-Delta Delta C(T)) Method. Methods 25: 402-408, 2001.

19. Koike A, Minamiguchi I, Fujimori K and Amano F: Nitric oxide is an important regulator of heme oxygenase-1 expression in the lipopolysaccharide and interferon- $\gamma$-treated murine macrophage-like cell line J774.1/JA-4. Biol Pharm Bull 38: 7-16, 2015.

20. Guzik TJ, Korbut R and Adamek-Guzik T: Nitric oxide and superoxide in inflammation and immune regulation. J Physiol Pharmacol 54: 469-487, 2003.

21. Chan AT, Ogino S and Fuchs CS: Aspirin and the risk of colorectal cancer in relation to the expression of COX-2. N Engl J Med 356: 2131-2142, 2007.

22. Boscá L, Zeini M, Través PG and Hortelano S: Nitric oxide and cell viability in inflammatory cells: A role for NO in macrophage function and fate. Toxicology 208: 249-258, 2005.
23. Guo AK, Hou YY, Hirata H, Yamauchi S, Yip AK, Chiam KH, Tanaka N, Sawada Y and Kawauchi K: Loss of p53 enhances $\mathrm{NF}-\kappa \mathrm{B}-$ dependent lamellipodia formation. J Cell Physiol 229: 696-704, 2014.

24. Beg AA, Finco TS, Nantermet PV and Baldwin AS Jr: Tumor necrosis factor and interleukin-1 lead to phosphorylation and loss of I kappa B alpha: A mechanism for NF-kappa B activation. Mol Cell Biol 13: 3301-3310, 1993.

25. Brown KL, Cosseau C, Gardy JL and Hancock RE: Complexities of targeting innate immunity to treat infection. Trends Immunol 28: 260-266, 2007.

26. Schröder NW, Opitz B, Lamping N, Michelsen KS, Zähringer U, Göbel UB and Schumann RR: Involvement of lipopolysaccharide binding protein, CD14, and Toll-like receptors in the initiation of innate immune responses by Treponema glycolipids. J Immunol 165: 2683-2693, 2000.

27. Koo JE, Park ZY, Kim ND and Lee JY: Sulforaphane inhibits the engagement of LPS with TLR4/MD2 complex by preferential binding to Cys133 in MD2. Biochem Biophys Res Commun 434: 600-605, 2013

28. Miller SI, Ernst RK and Bader MW: LPS, TLR4 and infectious disease diversity. Nat Rev Microbiol 3: 36-46, 2005.

29. Choi YH, Kim GY and Lee HH: Anti-inflammatory effects of cordycepin in lipopolysaccharide-stimulated RAW 264.7 macrophages through Toll-like receptor 4-mediated suppression of mitogen-activated protein kinases and NF- $\mathrm{KB}$ signaling pathways. Drug Des Devel Ther 8: 1941-1953, 2014.

30. Nijland R, Hofland T and van Strijp JA: Recognition of LPS by TLR4: Potential for anti-inflammatory therapies. Mar Drugs 12: 4260-4273, 2014.

31. Suganami T, Tanimoto-Koyama K, Nishida J, Itoh M, Yuan X, Mizuarai S, Kotani H, Yamaoka S, Miyake K, Aoe S, et al: Role of the Toll-like receptor 4/NF-kappaB pathway in saturated fatty acid-induced inflammatory changes in the interaction between adipocytes and macrophages. Arterioscler Thromb Vasc Biol 27: 84-91, 2007.

32. Dou W, Zhang J, Sun A, Zhang E, Ding L, Mukherjee S, Wei X, Chou G, Wang ZT and Mani S: Protective effect of naringenin against experimental colitis via suppression of Toll-like receptor 4/NF-kB signalling. Br J Nutr 110: 599-608, 2013. 